Smith, Martin M. ORCID:

https://orcid.org/0000-0002-4754-3032 and Saklofske, Donald H. (2017) The Structure of Multidimensional Perfectionism: Support for a Bifactor Model With a Dominant General Factor. Journal of Personality Assessment, 99 (3). pp. 297-303.

Downloaded from: http://ray.yorksj.ac.uk/id/eprint/2923/

The version presented here may differ from the published version or version of record. If you intend to cite from the work you are advised to consult the publisher's version: https://doi.org/10.1080/00223891.2016.1208209

Research at York St John (RaY) is an institutional repository. It supports the principles of open access by making the research outputs of the University available in digital form. Copyright of the items stored in RaY reside with the authors and/or other copyright owners. Users may access full text items free of charge, and may download a copy for private study or non-commercial research. For further reuse terms, see licence terms governing individual outputs. Institutional Repository Policy Statement

\title{
RaY
}

Research at the University of York St John

For more information please contact RaY at ray@yorksj.ac.uk 
The Structure of Multidimensional Perfectionism: Support for a Bifactor Model with a Dominant General Factor

Martin M. Smith and Donald H. Saklofske

University of Western Ontario

Accepted June 8, 2016 at Journal of Personality Assessment

\begin{abstract}
Author Note
Martin M. Smith and Donald Saklofske, Department of Psychology, University of Western Ontario. Correspondence cornering this article should be addressed to Martin M. Smith, Department of Psychology, University of Western Ontario, London N6A 5C2, Canada. E-mail: msmit454@uwo.ca.
\end{abstract}




\begin{abstract}
Evidence suggests perfectionism is a multidimensional construct comprised of two higher-order factors: perfectionistic strivings and perfectionistic concerns. However, the substantial overlap between perfectionistic strivings and perfectionistic concerns is problematic, as are the unanswered questions regarding the structure of perfectionism following removal of common variance. The present research addressed this through bifactor modeling. Three student samples $(N=742)$ completed Hewitt and Flett's (1991) Multidimensional Perfectionism Scale (HFMPS), Frost, Marten, Lahart, \& Rosenblate's (1990) Multidimensional Perfectionism Scale (FMPS), and Slaney, Rice, Mobley, Trippi, and Ashby's (2001) Almost Perfect Scale-Revised (APS-R). Greater support was consistently found for the bifactor model, relative to the two-factor model. Results suggest the bifactor model best represents the structure of perfectionism and provide preliminary support for the use of a general factor score. Researchers are cautioned that removal of general variance may render the reliability of specific factors (i.e., perfectionistic strivings and perfectionistic concerns) suspect.
\end{abstract}

Keywords: perfectionism; perfectionistic strivings; perfectionistic concerns; bifactor model 
The Structure of Multidimensional Perfectionism: Support for a Bifactor Model with a Dominant

\section{General Factor}

Accumulated evidence suggests perfectionism is best understood as a multidimensional construct (Hewitt, Flett, Besser, Sherry, \& McGee, 2003) comprised of two higher-order factors: perfectionistic strivings and perfectionistic concerns (see Stoeber \& Otto, 2006, for review). Perfectionistic strivings encompass a family of traits, including self-oriented perfectionism (demanding perfection of oneself; Hewitt \& Flett, 1991), order (organization and neatness; Slaney, Rice, Mobley, Trippi, \& Ashby, 2001), and personal standards (setting unreasonable high personal standards and goals; Frost, Marten, Lahart, \& Rosenblate, 1990). Perfectionistic concerns are comprised of a constellation of traits, including socially prescribed perfectionism (perceiving others as demanding perfection of oneself; Hewitt \& Flett, 1991), concern over mistakes (i.e., adverse reactions to failures; Frost et al., 1990), doubts about actions (doubts about performance abilities; Frost et al., 1990), discrepancy (the perceived difference between the standards one has and one's actual performance; Slaney et al., 2001), and other-oriented perfectionism (demanding perfection from others; Hewitt \& Flett, 1991).

Perfectionistic concerns are robustly associated with negative outcomes (e.g., depression; Stoeber \& Otto, 2006) and are longitudinal risk factors for psychological maladjustment (Smith, Sherry, Rnic, Saklofske, Enns, \& Gralnick, 2016a). In contrast, perfectionistic strivings are inconsistent predictors of psychological maladjustment. For example, prior research has shown that following removal of general variance, perfectionistic strivings are negatively associated with maladjustment (e.g., depression; Smith, Saklofske, Yan, and Sherry, 2015; see Stoeber \& Otto, for review). Indeed, some research suggests perfectionistic concerns suppress the 
association between perfectionistic strivings and positive outcomes (Hill, Huelsman, \& Araujo, 2010).

In general, past research has supported the validity of the two-factor model (Dunkley, Blankstein, Halsall, Williams, \& Winkworth, 2000; Dunkley, Blankstein, \& Berg, 2012; Stoeber \& Otto, 2006) which has been found to emerge from different measures (e.g., the Clinical Perfectionism Questionnaire; Stoeber \& Damian, 2014), and to generalize to non-English speaking samples (Smith, Saklofske, Yan, \& Sherry, 2016b). Even so, there remain unanswered questions regarding the structure of perfectionism. In particular, to what extent does a general factor account for common variance across core perfectionism dimensions? Additionally, what effect does the removal of general variance have on the structure of perfectionism?

We attempted to answer these questions through bifactor modeling. Given that perfectionistic strivings and perfectionistic concerns overlap substantially (e.g., $r=.58$ to .72 ; Dunkley et al., 2012), it is reasonable to assert that rather than two highly correlated perfectionism factors (perfectionistic strivings and perfectionistic concerns) there might be just a single general factor underlying responses to all indicator variables (i.e., perfectionism subscales). As well, the substantial overlap between perfectionistic strivings and perfectionistic concerns may hinder differential validity (DeMars, 2013). Bifactor modeling would rectify this given that in bifactor models specific factors are orthogonal and capture common variance amongst items not accounted for by a general factor. In addition, facets (i.e., elements of higherorder constructs) are specified as loading onto both a general factor and a specific factor. Relative to correlated factor models, bifactor models are computationally simpler to estimate and usually provide superior model fit (DeMars, 2013; Chen, West, \& Sousa, 2006). Nonetheless, for 
the general factor of perfectionism to be supported there would need to be significant positive loadings for all indicators (i.e., perfectionism subscales) on the general factor.

\section{The Present Research}

Only a limited number of perfectionism models have been evaluated and researchers rarely, if ever, attempt to disentangle perfectionism's common and specific components. Therefore, we evaluated an alternative structural model of perfectionism using nine subscales derived from Hewitt and Flett's (1991) Multidimensional Perfectionism Scale (HFMPS), Frost, et al.'s (1990) Multidimensional Perfectionism Scale (FMPS), and Slaney et al.'s (2001) Almost Perfect Scale-Revised (APS-R): self-oriented perfectionism, order, personal standards, high standards, socially prescribed perfectionism, concern over mistakes, doubts about actions, discrepancy, and other-oriented perfectionism. We conducted bifactor modeling to evaluate the proportion of total and common variance attributable to a general factor and specific factors (i.e., perfectionistic strivings and perfectionistic concerns), as well as to determine whether using a general factor score is justified. Thus, the present study was not merely focused on finding the model with the best fit, but also in using several indices such as omega hierarchical to provide information on the strength of the general factor, and reliability of specific factors (i.e., perfectionistic strivings and perfectionistic concerns) after controlling for variance attributable to the general factor (Jovanović, 2015).

\section{Method}

\section{Participants}

Three student samples were recruited from the Department of Psychology’s subject pool at a large university in central Canada. Sample 1 was comprised of 291 undergraduate students, and data were collected in late 2014. Sample 2 was comprised of 152 undergraduate students and 
was collected in the winter of 2015. Sample 3 included 305 undergraduate students and was collected in the spring of 2015.

The combined sample of 731 students (373 women and 358 men) had a mean age of 18.74 years $(S D=2.42)$. The mean age of women $(M=18.53, S D=1.49)$ differed significantly from men $(M=18.96, S D=3.10), t(725)=2.45, p<.05$. However, the effect size of this difference (Cohen's $d=.18$ ) was negligible according to Cohen's (1992) guidelines for small, medium, and large effect sizes $(r=.10, .30, .50$, respectively; see Ferguson, 2009). The majority of the sample was in their first year of study $(82.3 \% ; \mathrm{N}=631)$. Self-reported ethnicities were 52.3\% White, 16.3\% Chinese, 5.6\% South Asian, 5.2\% Multiracial, 3\% East Indian, 2.7\% Korean, 2.5\% Arab, 1.5\% South East Asian, 1.4\%, and 9\% other. Detailed statistics regarding gender differences are presented in the Supplemental Material.

\section{Measures}

\section{Perfectionistic Strivings}

Perfectionistic strivings were measured using four subscales: the 5-item short form of Hewitt and Flett's (1991) Multidimensional Perfectionism Scale (HFMPS) Self-Oriented Perfectionism subscale (HFMPS-SOP; e.g., "I strive to be as perfect as I can be"; see Hewitt, Habke, Lee-Baggley, Sherry, \& Flett, 2008); Frost et al.’s (1990) 4-item short-form Multidimensional Perfectionism Scale Personal Standards subscale (FMPS-PS; e.g., "I set higher goals than most people"; see Cox, Enns, \& Clara, 2002); Slaney et al.'s (2001) 4-item Almost Perfect Scale-Revised (APS-R) Order subscale (APS-R-O; e.g., "I like to always be organized and disciplined"); and Slaney et al.’s (2001) APS High Standards subscale (APS-R-S; e.g., "I set very high standards for myself'). Participants responded to the HFMPS-SOP, APS-R-O, and 
APS-R-S using a 7-point scale ranging from 1 (strongly disagree) to 7 (strongly agree), and to the FMPS-PS using a 5-point scale ranging from 1 (strongly disagree) to 5 (strongly agree).

Research attests to the reliability and validity of these subscales. Cronbach's alpha for the HFMPS-SOP typically ranges between .75 to .85 (see Hewitt et al., 2008). Smith et al. (2016b) reported an alpha of .84 for the FMPS-PS. Additionally, the APS-S and APS-R-O have been shown to have adequate internal consistency and temporal stability (Slaney et al., 2001), as well as convergent, divergent, structural, and predictive validity (Rice, Ashby, \& Slaney, 2007; Slaney et al., 2001). In the present study the reliability (Cronbach's alpha) values for HFMPSSOP, FMPS-PS, APS-R-O, and APS-R-S were all adequate ( $\alpha>.70$; see Table 1$)$.

\section{Perfectionistic Concerns}

Perfectionistic concerns were measured using five subscales: the 5-item short form of Hewitt and Flett's (1991) HFMPS Socially Prescribed Perfectionism subscale (HFMPS-SPP; e.g., "People expect more from me than I am capable of giving"; see Hewitt, Habke, LeeBaggley, Sherry, \& Flett, 2008); the 5-item short form of Frost et al.'s (1990) FMPS Concerns Over Mistakes subscale (FMPS-COM; e.g., "If I fail at work/school I am a failure as a person”; see Cox, Enns, \& Clara, 2002); Frost et al.’s (1990) 4-item FMPS Doubts About Actions subscale (FMPS-DAA; e.g., "I usually have doubts about the simple everyday things I do"; see Cox, Enns, \& Clara, 2002); Slaney et al.'s (2001) 12-item APS-R Discrepancy subscale (APS-RD; e.g., "I am hardly every satisfied with my performance"); and the 5-item short form of Hewitt and Flett's (1991) HFMPS Other-Oriented Perfectionism subscale (HFMPS-OOP; e.g., "I cannot stand to see people close to me make mistakes"; see Hewitt, Habke, Lee-Baggley, Sherry, \& Flett, 2008) The HFMPS-SPP, APS-R-D, and HFMPS-OOP employ a 7-point scale ranging 
from 1 (strongly disagree) to 7 (strongly agree), while the FMPS-COM and FMPS-DAA both use a 5-point scale ranging from 1 (strongly disagree) to 5 (strongly agree).

Support for the reliability and validity of the HFMPS-SPP, HFMPS-OOP, FMPS-COM, FMPS-DAA, and APS-R-D has been reported in several studies. Sherry et al. (2010) reported a Cronbach's alpha of .76 for the HFMPS-SPP. Hewitt et al. (2008) reported a Cronbach's alpha of .84 for the HFMPS-OOP. Further, support for the reliability, as well as validity, of the HFMPSSPP and HFMPS-OOP is reported in Hewitt et al. (2008). Additionally, Mackinnon and Sherry (2012) reported a Cronbach's alpha from .87-.89 for the FMPS-COM and Rice and Dellwo (2011) found a Cronbach's alpha of .78 for the FMPS-DAA. A summary of evidence in support of the reliability and validity of the APS-D can be found in Slaney, Rice, and Ashby (2002), as well as Flett and Hewitt (2015). In the present study the reliability (Cronbach's alpha) values for the HFMPS-SPP HFMPS-OOP, FMPS-COM, FMPS-DAA, and APS-D were adequate $(\alpha>.70$; see Table 1).

\section{Data Analytic Strategy}

Confirmatory factor analysis (CFA) and structural equation modeling (SEM) were conducted using Mplus version 7.4 (Muthén \& Muthén, 1998-2010). All analysis employed robust maximum likelihood estimation (MLR). The Satorra-Bentler Scaled chi-square difference test $\left(\Delta X^{2}\right)$ was used for all model comparisons (Gibbons \& Hedeker, 1992). In addition to chisquare, the following approximate fit indices for model evaluation were used: the root mean error of approximation (RMSEA), the comparative fit index (CFI), and the Tucker-Lewis Index (TLI).

The RMSEA is an indicator of the level of misfit per degrees of freedom, with values of .08 or below being acceptable and values of .05 or less indicating close model fit. In evaluating 
RMSEA, the $90 \%$ confidence interval is used to assess both "close fit" and "poor fit" hypotheses (see Kline, 2015). Optimally, the lower bound of the confidence interval will include zero, but the close fit hypothesis is supported in distinguishing that a confidence interval includes the .05 value and has a non-significant $\mathrm{p}$-value (>.05). The poor fit hypothesis is evaluated by determining that the upper bonds confidence interval does not exceed the threshold for poor fit or a .10 value. Additionally, regarding CFI and TLI, values in the range of .95 or above suggest good model fit, and values between .90 and .95 suggest marginally acceptable model fit (Hu \& Bentler, 1998). For the bifactor model, the omega coefficient, the omega hierarchical coefficient, and the omega subscale coefficient was computed which enabled an evaluation of how much total and common variance in perfectionism is attributed to the general factor and specific factors, as well as to examine whether forming a total perfectionism score is justified (Reise, 2012; Reise, Bonifay, \& Haviland, 2013; Reise, Moore, \& Haviland, 2010). We also evaluated multigroup invariance of the bifactor model across the three samples, as well as across men and women.

Several competing models of perfectionism were tested: (1) the single factor model with subscales loading onto one underlying factor; (2) the two-factor model (both orthogonal and oblique) with two dimensions: perfectionistic strivings (comprising self-oriented perfectionism, personal standards, high standards, order) and perfectionistic concerns (comprising socially prescribed perfectionism, concern over mistakes, doubts about actions, discrepancy, and otheroriented perfectionism); (3) the bifactor model with two specific factors (perfectionistic strivings and perfectionistic concerns) and a general factor. The decision to use the chi-square statistic to compare the fit of correlated factor models to bifactor models is defensible as the correlated factor model is nested within the bifactor model (Reise, 2012). Specifically, the correlated factor 
model can be derived from the bifactor model by fixing the loadings on the general factor to zero and freeing the orthogonality constraints on the specific factors (see Reise, 2012, for a detailed discussion). To increase confidence in our findings, we also used the Bayesian Information Criterion (BIC) to evaluate the fit of all models tested. For BIC, the lower values across model comparisons were considered to represent relatively better fit (Betts, Pickart, \& Heistad, 2011).

\section{Results}

\section{Descriptive Statistics}

Means, standard deviations, bivariate correlations, and Cronbach's alpha are presented in Table 1 . Women relative to men reported significantly lower other-oriented perfectionism (Cohen's $d=.29$ ), and significantly greater personal standards (Cohen's $d=-.21$ ), and discrepancy (Cohen's $d=-.16$ ). Detailed statistics regarding gender differences are presented in the Supplemental Material.

\section{Confirmatory Factor Analysis}

As shown in Table 2, the one-factor and two-factor models without error covariances yielded poor fit to the data in each of the three samples. The inspection of residual moments indicated that there were strongly correlated residuals between order and personal standards, order and high standards, and high standards and discrepancy. Allowing these residual correlations to inter-correlate resulted in lower BIC values (see Table 2), as well as a significantly better model fit: $\Delta X_{(3)}^{2}=113.68, p<.001$. These findings suggest that the measurement model is degraded when significantly correlated residuals are left out. Consequently, the two-factor model with correlated errors was used as the baseline model upon which the bifactor model was compared (Betts, Pickart, \& Heistad, 2011; Jovanović, 2015). However, the refined two-factor model with correlated errors still fit poorly. 
In contrast to the two-factor model, across three samples the bifactor model demonstrated good fit to the data with most fit indices being above the threshold for acceptable model fit. Additionally, the bifactor models consistently had the lowest BIC values (see Table 2) and fitted the data significantly better than the refined two-factor models (for Sample 1: $\Delta X_{(8)}^{2}=60.88, p$ $<.001$; for Sample 2: $\Delta X_{(8)}^{2}=39.10, p<.001$; for Sample 3: $\left.\Delta X_{(8)}^{2}=102.35, p<.001\right)$. Thus, results suggested that the bifactor model best represented the structure of perfectionism.

We investigated multigroup invariance of the bifactor model across samples. The fit of the configural model was acceptable: MLR $\chi^{2}{ }_{(45)}=95.49$, RMSEA $=.067(90 \% \mathrm{CI}=.048, .086$; Pclose $=.066), \mathrm{CFI}=.984, \mathrm{TLI}=.961$. Constraining factor loadings to be equal across the three samples (i.e., measurement invariance; Kline, 2015) did not result in a significant loss of fit: $\Delta X^{2}{ }_{(30)}=31.35, p=.398$. We also investigated multigroup invariance of the bifactor model across gender. The fit of the configural model was again acceptable: MLR $\chi_{(10)}^{2}=21.29$, RMSEA $=.056(90 \% \mathrm{CI}=.022, .089 ;$ Pclose $=.346), \mathrm{CFI}=.995, \mathrm{TLI}=.981$. Furthermore, constraining factor loadings to be equal across men and women did not result in a significant loss of fit: $\Delta X_{(11)}^{2}=23.50, p=.080$. Results support the generalizability of the bifactor model across the three samples and across gender. Thus, for the remainder of analyses, the three samples were merged into a single group comprised of both men and women $(N=742)$.

\section{The Bifactor Model of Perfectionism}

Table 3 presents factor loadings, sources of variance, and reliability estimates for the general factor and two specific factors (perfectionistic strivings and perfectionistic concerns). Socially prescribed perfectionism, concern over mistakes, doubts about actions, discrepancy, other-oriented perfectionism, self-oriented perfectionism, personal standards, high standards, and order all had strong loadings (i.e., $\geq .40$ ) on the general factor. Additionally, with the exception 
of high standards and order, all perfectionism indicators had higher loadings on the general factor relative to specific factors. Furthermore, after controlling for the general factor, concern over mistakes, discrepancy, and doubts about actions loadings on the specific perfectionistic concerns factor remained significant. Moreover, after controlling for the general factor, all indicator loadings for the specific perfectionistic strivings factor remained salient.

The general factor explained $38.6 \%$ of the total variance, while the specific perfectionistic concerns and specific perfectionistic strivings factors explained $4.4 \%$ and $9.7 \%$ of the total variance, respectively. Additionally, the general factor accounted for $73.2 \%$ of the common variance. The value of $\omega_{\mathrm{h}}$ (coefficient omega hierarchical) indicated that $77 \%$ of the variance of the composite perfectionism score was attributable to a general factor. Omega hierarchical for subscale scores $\left(\omega_{\mathrm{s}}\right)$, which indicates the reliability of specific factors after controlling for the general factor, was .04 for the specific perfectionistic concerns factor and .36 for the specific perfectionistic strivings factor. As well, $40.9 \%$ of the reliable variance in perfectionistic strivings and $4.6 \%$ of the reliable variance in perfectionistic concerns (i.e., $\left.\omega_{\mathrm{s} /} / \omega\right)$ was independent of the general factor. Moreover, the bifactor model accounted for $52.7 \%$ of the total variance, whereas the two-factor model and one-factor model accounted for $48.1 \%$ and $41.8 \%$ of the total variance, respectively. Thus, results again suggest the bifactor model best represents the structure of perfectionism and suggests that the use of a general factor score is justified. However, results also indicate that perfectionistic concerns, and to a lesser extent perfectionistic strivings, are unreliable factors following the removal of general variance.

\section{Discussion}

The aim of the present research was to evaluate a bifactor model of perfectionism as a viable alternative to the two-factor model. Findings indicate that a bifactor model with a general 
factor and two specific factors (perfectionistic strivings and perfectionistic concerns) best represents the structure of perfectionism. Furthermore, results suggest the majority of common variance amongst core perfectionism dimensions is attributable to a general factor. In particular, a strong general factor appears to be present amongst self-oriented perfectionism, concern over mistakes, doubts about actions, discrepancy, other-oriented perfectionism, personal standards, high standards, order, and self-oriented perfectionism. As well, results suggest that a substantial portion of variance is independent of the general factor and attributable to a specific perfectionistic strivings factor.

Nonetheless, perfectionistic strivings and perfectionistic concerns were unreliable factors following removal of general variance. In particular, the omega subscale coefficient for both the specific perfectionistic strivings factor and the specific perfectionistic concerns factors fell short of .50, suggesting specific factor scores for perfectionistic strivings and perfectionistic concerns are unreliable (see Reise, Bonifay, \& Haviland, 2013). In contrast, the omega hierarchical coefficient for the general factor suggested that the use of a general factor score is defensible. Taken together these findings suggest greater care is needed when examining the effects of perfectionistic strivings and perfectionistic concerns following removal of shared variance (e.g., Hill et al., 2010; Stoeber \& Otto, 2006). Indeed, the unreliability of the specific perfectionistic strivings factor calls into question the claimed 'adaptiveness' of perfectionistic strivings given that these findings hinge on the removal of general variance (e.g., Stoeber \& Corr, 2016). Additionally, relative to the bifactor model, the two-factor model has notable limitations. In particular, unlike the bifactor model, the two-factor model is unable to clarify the relative importance of general and specific components of perfectionism. Moreover, the two-factor 
model provides no means of evaluating whether perfectionistic strivings and perfectionistic concerns remain stable factors after controlling for general variance.

Moving forward, we encourage researchers to evaluate the utility of the two-factor model via bifactor modeling before only using perfectionistic strivings and perfectionistic concerns as predictors. Failure to investigate a bifactor model prior to interpreting the effects of perfectionistic strivings and perfectionistic concerns may lead to misguided inferences. If, as in the present study, bifactor modeling reveals a dominant general factor with weak specific factors, we advise researchers to use either the general factor or scores derived from lower-level perfectionism dimensions (e.g., self-oriented perfectionism). It should be noted that in the majority of circumstances, the latter will be more fruitful given that lower-order perfectionism dimensions capture specific and predictive variance (Paunonen, Haddock, Forsterling, \& Keinonen, 2003).

\section{Future Directions and Limitations}

A richer, more fine-grained, analysis of the structure of perfectionism using long form measures is needed. Additionally, a limitation inherent to all bifactor models is that they necessitate the use of structural equation modeling and cannot be examined using traditional statistical approaches such as multiple regression. Furthermore, the generalizability of our findings require replication beyond student samples. Research is also needed on whether specific factor scores, or a weighted combination of specific and general factor scores should be reported (DeMars, 2013). Moreover, additional research evaluating bifactor models derived from different combinations of perfectionism indicators is required. Finally, researchers should consider investigating whether the bifactor model changes the conceptual meaning of specific factors to such an extent that they cease to be relevant to perfectionism research. 


\section{References}

Betts, J., Pickart, M., \& Heistad, D. (2011). Investigating early literacy and numeracy: Exploring the utility of the bifactor model. School Psychology Quarterly, 26, 97.

Chen, F. F., West, S. G., \& Sousa, K. H. (2006). A comparison of bifactor and second-order models of quality of life. Multivariate Behavioral Research, 41, 189-225.

Cox, B. J., Enns, M. W., \& Clara, I. P. (2002). The multidimensional structure of perfectionism in clinically distressed and college student samples. Psychological Assessment, 14, 365.

DeMars, C. E. (2013). A tutorial on interpreting bifactor model scores. International Journal of Testing, 13, 354-378.

Dunkley, D. M., Blankstein, K. R., \& Berg, J. L. (2012). Perfectionism dimensions and the fivefactor model of personality. European Journal of Personality, 26, 233-244.

Dunkley, D. M., Blankstein, K. R., Halsall, J., Williams, M., \& Winkworth, G. (2000). The relation between perfectionism and distress: Hassles, coping, and perceived social support as mediators and moderators. Journal of Counseling Psychology, 47, 437-453.

Ferguson, C. J. (2009). An effect size primer: A guide for clinicians and researchers. Professional Psychology: Research and Practice, 40, 532.

Flett, G., \& Hewitt, P. (2015). Measures of perfectionism. In G. J. Boyle, D. H. Saklofske \& G. Mathews (Eds.), Personality and Social Psychology Constructs (pp. 595-617). Academic Press.

Frost, R. O., Marten, P., Lahart, C., \& Rosenblate, R. (1990). The dimensions of perfectionism. Cognitive Therapy and Research, 14, 449-468.

Gibbons, R. D., \& Hedeker, D. R. (1992). Full-information item bi-factor analysis. Psychometrika, 57, 423-436. 
Hewitt, P. L., \& Flett, G. L. (1991). Perfectionism in the self and social contexts:

conceptualization, assessment, and association with psychopathology. Journal of Personality and Social Psychology, 60, 456.

Hewitt, P. L, \& Flett, G. L. (2004). The Multidimensional Perfectionism Scale: Manual. Toronto: Multi-Health Systems, Inc.

Hewitt, P. L., Flett, G. L., Besser, A., Sherry, S. B., \& McGee, B. (2003). Perfectionism is multidimensional: A reply to Shafran, Cooper, and Fairburn (2003). Behaviour Research and Therapy, 41, 1221-1236.

Hewitt, P. L., Habke, A. M., Lee-Baggley, D. L., Sherry, S. B., \& Flett, G. L. (2008). The impact of perfectionistic self-presentation on the cognitive, affective, and physiological experience of a clinical interview. Psychiatry, 71, 93-122.

Hill, R. W., Huelsman, T. J., \& Araujo, G. (2010). Perfectionistic concerns suppress associations between perfectionistic strivings and positive life outcomes. Personality and Individual Differences, 48, 584-589.

Hu, L. T., \& Bentler, P. M. (1998). Fit indices in covariance structure modeling: Sensitivity to underparameterized model misspecification. Psychological Methods, 3, 424.

Jovanović, V. (2015). A bifactor model of subjective well-being: A re-examination of the structure of subjective well-being. Personality and Individual Differences, 87, 45-49.

Kline, R. B. (2015). Principles and practice of structural equation modeling. Guilford publications.

Mackinnon, S. P., \& Sherry, S. B. (2012). Perfectionistic self-presentation mediates the relationship between perfectionistic concerns and subjective well-being: A three-wave longitudinal study. Personality and Individual Differences, 53, 22-28. 
Musek, J. (2007). A general factor of personality: Evidence for the Big One in the five-factor model. Journal of Research in Personality, 41, 1213-1233.

Muthén, L., \& Muthén, B. (2010). Mplus user's guide ( $6^{\text {th }}$ ed.). Los Angeles, CA: Muthén \& Muthén.

Reise, S. P. (2012). The rediscovery of bifactor measurement models. Multivariate Behavioral Research, 47, 667-696.

Reise, S. P., Bonifay, W. E., \& Haviland, M. G. (2013). Scoring and modeling psychological measures in the presence of multidimensionality. Journal of Personality Assessment, 95, 129-140.

Reise, S. P., Moore, M., \& Haviland, G. (2010). Bifactor models and rotations: Exploring the extent to which multidimensional data yield univocal scale scores. Journal of Personality Assessment, 92, 544-559.

Rice, K. G., Ashby, J. S., \& Slaney, R. B. (2007). Perfectionism and the five-factor model of personality. Assessment, 14, 385-398.

Sherry, S. B., Hewitt, P. L., Sherry, D. L., Flett, G. L., \& Graham, A. R. (2010). Perfectionism dimensions and research productivity in psychology professors: Implications for understanding the (mal)adaptiveness of perfectionism. Canadian Journal of Behavioural Science, 42, 273.

Slaney, R. B., Rice, K. G., \& Ashby, J. S. (2002). A programmatic approach to measuring perfectionism: The Almost Perfect Scales. In G. L. Flett \& P. L. Hewitt (Eds.), Perfectionism: Theory, research, and treatment (pp. 63-83). Washington, DC: American Psychological Association.

Slaney, R. B., Rice, K. G., Mobley, M., Trippi, J., \& Ashby, J. S. (2001). The revised almost 
perfect scale. Measurement and Evaluation in Counseling and Development, 34, 130145.

Smith, M. M., Saklofske, D. H., Yan, G., \& Sherry, S. B. (2015). Perfectionistic strivings and perfectionistic concerns interact to predict negative emotionality: Support for the tripartite model of perfectionism in Canadian and Chinese university students. Personality and Individual Differences, 81, 141-147.

Smith, M. M., Saklofske, D. H., Yan, G., \& Sherry, S. B. (2016a). Cultural similarities in perfectionism: Perfectionistic strivings and concerns generalize across Chinese and Canadian groups. Measurement and Evaluation in Counseling and Development, 49, 6376.

Smith, M. M., Sherry, S.B., Rnic, K., Saklofske, D. H., Enns, M. W., \& Gralnick, T. (2016b). Are perfectionism dimensions vulnerability factors for depressive symptoms after controlling for neuroticism? A meta-analysis of 10 longitudinal studies. European Journal of Personality, 30, 201-212.

Stoeber, J., \& Corr, P. J. (2016). A short empirical note on perfectionism and flourishing. Personality and Individual Differences, 90, 50-53.

Stoeber, J., \& Damian, L. (2014). The clinical perfectionism questionnaire: Further evidence of two factors capturing perfectionistic strivings and perfectionistic concerns. Personality and Individual Differences, 61-62, 38-42.

Stoeber, J., \& Otto, K. (2006). Positive conceptions of perfectionism: Approaches, evidence, challenges. Personality and Social Psychology Review, 10, 295-319. 
Table 1

Bivariate correlations and Cronbach's alphas

\begin{tabular}{|c|c|c|c|c|c|c|c|c|c|}
\hline & 1 & 2 & 3 & 4 & 5 & 6 & 7 & 8 & $\alpha$ \\
\hline \multicolumn{10}{|l|}{ Sample 1} \\
\hline 1. Socially prescribed perfectionism (HFMPS) & 1 & & & & & & & & .79 \\
\hline 2. Concern over mistakes (FMPS) & $.65^{*}$ & 1 & & & & & & & .82 \\
\hline 3. Doubts about actions (FMPS) & $.46^{*}$ & $.65^{*}$ & 1 & & & & & & .76 \\
\hline 4. Discrepancy (APS-R) & $.51^{*}$ & $.68^{*}$ & $.65^{*}$ & 1 & & & & & .93 \\
\hline 5. Other-oriented perfectionism (HFMPS) & $.57^{*}$ & $.55^{*}$ & $.41^{*}$ & $.41^{*}$ & 1 & & & & .82 \\
\hline 6. Self-oriented perfectionism (HFMPS) & $.62^{*}$ & $.58^{*}$ & $.48^{*}$ & $.49^{*}$ & $.55^{*}$ & 1 & & & .87 \\
\hline 7. Personal standards (FMPS) & $.57^{*}$ & $.62^{*}$ & $.51^{*}$ & $.48^{*}$ & $.50^{*}$ & $.76^{*}$ & 1 & & .82 \\
\hline 8. High standards (APS-R) & $.41^{*}$ & $.46^{*}$ & $.34^{*}$ & $.53^{*}$ & $.25^{*}$ & $.63^{*}$ & $.69^{*}$ & 1 & .79 \\
\hline 9. Order (APS-R) & .16 & .16 & .12 & .16 & .13 & $.34^{*}$ & $.27^{*}$ & $.48^{*}$ & .85 \\
\hline \multicolumn{10}{|l|}{ Sample 2} \\
\hline 1. Socially prescribed perfectionism (HFMPS) & 1 & & & & & & & & .90 \\
\hline 2. Concern over mistakes (FMPS) & $.70^{*}$ & 1 & & & & & & & .82 \\
\hline 3. Doubts about actions (FMPS) & $.61^{*}$ & $.70^{*}$ & 1 & & & & & & .78 \\
\hline 4. Discrepancy (APS-R) & $.58^{*}$ & $.71^{*}$ & $.73^{*}$ & 1 & & & & & .95 \\
\hline 5. Other-oriented perfectionism (HFMPS) & $.61^{*}$ & $.48^{*}$ & $.39^{*}$ & $.41^{*}$ & 1 & & & & .72 \\
\hline 6. Self-oriented perfectionism (HFMPS) & $.66^{*}$ & $.54^{*}$ & $.48^{*}$ & $.57^{*}$ & $.51^{*}$ & 1 & & & .90 \\
\hline 7. Personal standards (FMPS) & $.62^{*}$ & $.55^{*}$ & $.50^{*}$ & $.48^{*}$ & $.52^{*}$ & $.74^{*}$ & 1 & & .72 \\
\hline 8. High standards (APS-R) & $.53^{*}$ & $.39^{*}$ & $.31^{*}$ & $.45^{*}$ & $.39^{*}$ & $.71^{*}$ & $.68^{*}$ & 1 & .87 \\
\hline 9. Order (APS-R) & $.29^{*}$ & .28 & .13 & $.31^{*}$ & $.23^{*}$ & $.53^{*}$ & $.37^{*}$ & $.65^{*}$ & .87 \\
\hline \multicolumn{10}{|l|}{ Sample 3} \\
\hline 1. Socially prescribed perfectionism (HFMPS) & 1 & & & & . & & & & .88 \\
\hline 2. Concern over mistakes (FMPS) & $.54^{*}$ & 1 & & & & & & & .79 \\
\hline 3. Doubts about actions (FMPS) & $.43^{*}$ & $.60^{*}$ & 1 & & & & & & .78 \\
\hline 4. Discrepancy (APS-R) & $.42^{*}$ & $.64^{*}$ & $.59^{*}$ & 1 & & & & & .94 \\
\hline 5. Other-oriented perfectionism (HFMPS) & $.58^{*}$ & $.48^{*}$ & $.28^{*}$ & $.35^{*}$ & 1 & & & & .80 \\
\hline 6. Self-oriented perfectionism (HFMPS) & $.59^{*}$ & $.51^{*}$ & $.34^{*}$ & $.39^{*}$ & $.53^{*}$ & 1 & & & .84 \\
\hline 7. Personal standards (FMPS) & $.48^{*}$ & $.57^{*}$ & $.38^{*}$ & $.41^{*}$ & $.45^{*}$ & $.70^{*}$ & 1 & & .80 \\
\hline 8. High standards (APS-R) & $.33^{*}$ & $.29^{*}$ & $.17^{*}$ & $.38^{*}$ & $.28^{*}$ & $.63^{*}$ & $.60^{*}$ & 1 & .88 \\
\hline 9. Order (APS-R) & .09 & .10 & .09 & $.19^{*}$ & $.12^{*}$ & $.33^{*}$ & $.15^{*}$ & $.47^{*}$ & .84 \\
\hline
\end{tabular}

Note. HFMPS = Hewitt and Flett's (1991) Multidimensional Perfectionism Scale; FMPS = Frost's et al.'s (1990) Multidimensional Perfectionism

Scale; APS-R= Slaney et al.'s (2001) Almost Perfect Scale-Revised. $\alpha=$ Cronbach's alpha. ${ }^{*} p<.001$. 
Table 2

Model fit across samples

\begin{tabular}{|c|c|c|c|c|c|c|c|}
\hline \multirow[b]{2}{*}{ Models (M) } & \multirow[b]{2}{*}{$X^{2}$} & \multicolumn{5}{|c|}{ Model Fit } & \multirow[b]{2}{*}{ BIC } \\
\hline & & $\mathrm{df}$ & RMSEA [90\% CI] & Pclose & CFI & TLI & \\
\hline \multicolumn{8}{|l|}{ Sample 1} \\
\hline M1: One-factor & $296.28^{*}$ & 27 & $.180[.162, .199]$ & .000 & .794 & .725 & 7038.73 \\
\hline M2: Two-factor orthogonal & $386.29^{*}$ & 27 & $.208[.190, .227]$ & .000 & .725 & .634 & 7149.07 \\
\hline M3: Two-factor oblique & $199.35^{*}$ & 26 & $.147[.129, .167]$ & .000 & .867 & .816 & 6951.09 \\
\hline M4: Two-factor oblique CE permitted & $104.62^{*}$ & 23 & $.108[.087, .129]$ & .000 & .938 & .902 & 6883.05 \\
\hline M5: Bi-factor CE permitted & 29.98 & 15 & $.057[.026, .087]$ & .315 & .989 & .972 & 6842.68 \\
\hline \multicolumn{8}{|l|}{ Sample 2} \\
\hline M1: One-factor & $201.04^{*}$ & 27 & $.212[.185, .239]$ & .000 & .763 & .683 & 3418.99 \\
\hline M2: Two-factor orthogonal & $189.34^{*}$ & 27 & $.204[.177, .232]$ & .000 & .779 & .705 & 3438.00 \\
\hline M3: Two-factor oblique & $110.23^{*}$ & 26 & $.150[.122, .179]$ & .000 & .885 & .841 & 3363.03 \\
\hline M4: Two-factor oblique CE permitted & 78.34 & 23 & $.129[.099, .161]$ & .000 & .924 & .882 & 3344.09 \\
\hline M5: Bi-factor CE permitted & 32.79 & 15 & $.091[.048, .133]$ & .057 & .976 & .942 & 3326.82 \\
\hline \multicolumn{8}{|l|}{ Sample 3} \\
\hline M1: One-factor & $290.28^{*}$ & 27 & $.181[.163, .200]$ & .000 & .744 & .659 & 7276.08 \\
\hline M2: Two-factor orthogonal & $295.86^{*}$ & 27 & $.183[.165, .202]$ & .000 & .739 & .652 & 7309.07 \\
\hline M3: Two factor oblique & $180.19^{*}$ & 26 & $.141[.122, .161]$ & .000 & .850 & .793 & 7169.96 \\
\hline M4: Two-factor oblique CE permitted & $140.23^{*}$ & 23 & $.131[.111, .152]$ & .000 & .886 & .822 & 7145.92 \\
\hline M5: Bi-factor model CE permitted & 32.79 & 15 & $.063[.033, .093]$ & .208 & .983 & .959 & 7068.30 \\
\hline \multicolumn{8}{|l|}{ Combined sample } \\
\hline M1: One-factor & $655.99^{*}$ & 27 & $.178[.166, .190]$ & .000 & .783 & .711 & 17580.32 \\
\hline M2: Two-factor orthogonal & $741.52^{*}$ & 27 & $.188[.177, .200]$ & .000 & .758 & .677 & 17760.20 \\
\hline M3: Two factor oblique & $373.60^{*}$ & 26 & $.134[.122, .146]$ & .000 & .882 & .837 & 17333.21 \\
\hline M4: Two-factor oblique CE permitted & $261.23^{*}$ & 23 & $.118[.105, .131]$ & .000 & .919 & .874 & 17222.56 \\
\hline M5: Bi-factor model CE permitted & $45.92^{*}$ & 15 & $.052[.036, .070]$ & .377 & .990 & .975 & 17022.65 \\
\hline
\end{tabular}

Note. CE $=$ correlated errors. $X^{2}=$ robust maximum likelihood chi-square; RMSEA = root mean square error of approximation; Pclose = probability RMSEA $\leq .05 ; \mathrm{CFI}=$ comparative fit index; TLI $=$ Tuker-Lewis index; $\mathrm{BIC}=$ Bayesian information criterion . ${ }^{*} p<.001$ 
Table 3

Factor loadings and sources of variance in perfectionism.

\begin{tabular}{|c|c|c|c|c|c|c|}
\hline \multirow[b]{2}{*}{ Indicator } & \multirow{2}{*}{$\begin{array}{c}\text { One-factor } \\
\text { GFP }\end{array}$} & \multicolumn{2}{|c|}{ Two-factor } & \multicolumn{3}{|c|}{ Bifactor } \\
\hline & & PS & PS & GFP & $\mathrm{PC}$ & PS \\
\hline Socially prescribed perfectionism (HFMPS) & $.75^{*}$ & $.74^{*}$ & - & $.81^{*}$ & -.04 & - \\
\hline Concern over mistakes (FMPS) & $.78^{*}$ & $.87^{*}$ & - & $.78^{*}$ & $.34^{*}$ & - \\
\hline Doubts about actions (FMPS) & $.65^{*}$ & $.73^{*}$ & - & $.62^{*}$ & $.50^{*}$ & - \\
\hline Discrepancy (APS-R) & $.68^{*}$ & $.76^{*}$ & - & $.64^{*}$ & $.51^{*}$ & - \\
\hline Other-oriented perfectionism (HFMPS) & $.64^{*}$ & $.62^{*}$ & - & $.72^{*}$ & -.14 & - \\
\hline Self-oriented perfectionism (HFMPS) & $.82^{*}$ & - & $.87^{*}$ & $.74^{*}$ & - & $.44^{*}$ \\
\hline Personal standards (FMPS) & $.80^{*}$ & - & $.87^{*}$ & $.71^{*}$ & - & $.48^{*}$ \\
\hline High standards (APS-R) & $.64^{*}$ & - & $.74^{*}$ & $.48^{*}$ & - & $.67^{*}$ \\
\hline Order (APS-R) & $.32^{*}$ & - & $.41^{*}$ & $.22^{*}$ & - & $.50^{*}$ \\
\hline$\%$ total variance & 41.8 & 22.9 & 25.2 & 38.6 & 4.4 & 9.7 \\
\hline \multirow{3}{*}{$\%$ common variance } & - & 47.6 & 52.4 & 73.2 & 8.4 & 18.4 \\
\hline & - & $\omega=.87$ & $\omega=.87$ & $\omega=.86$ & $\omega=.87$ & $\omega=.88$ \\
\hline & - & - & - & $\omega_{\mathrm{h}}=.77$ & $\omega_{\mathrm{s}}=.04$ & $\omega_{\mathrm{s}}=.36$ \\
\hline
\end{tabular}

Note. HFMPS = Hewitt and Flett's (1990) Multidimensional Perfectionism Scale Short Form (see Hewitt et al., 2008); FMPS-SF = Frost et al.'s (1990) Multidimensional Perfectionism Scale; FMPS = Frost et al.'s (1990) Multidimensional Perfectionism Scale; APS-R = Slaney et al.'s (2001) Almost Perfect Scale-Revised; GFP = General Factor of Perfectionism; PS = perfectionistic strivings; PC $=$ perfectionistic concerns; $\omega=$ omega coefficient; $\omega_{\mathrm{h}}=$ omega hierarchical; $\omega_{\mathrm{s}}=$ omega subscale. ${ }^{*} p<.001$ 

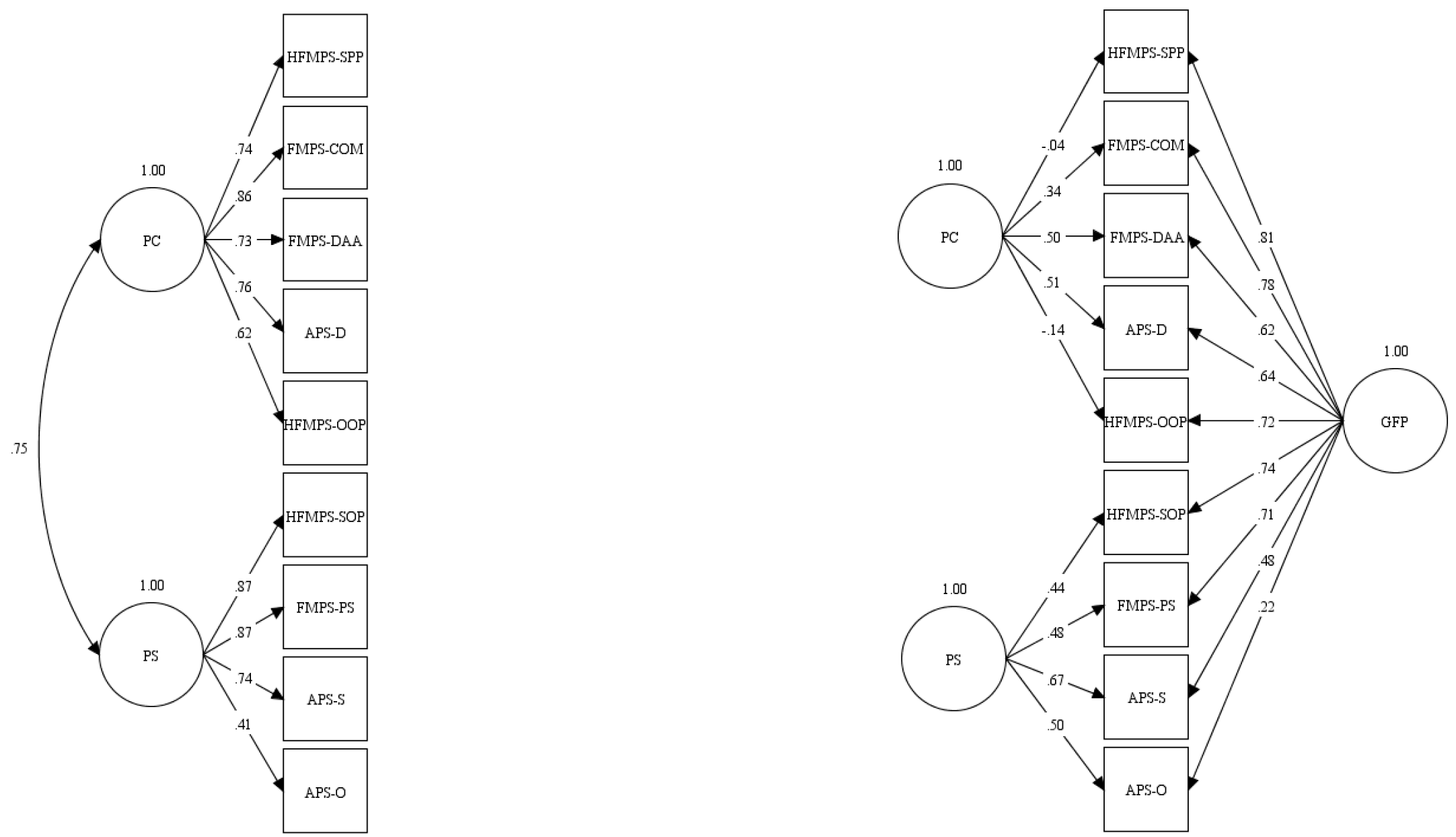

Figure 1. Diagrams of the two-factor oblique (left) and bifactor (right) models for the combined sample. All estimates are standardized. PS = perfectionistic strivings; PC = perfectionistic concerns; GFP = general factor of perfectionism; HFMPS = Hewitt and Flett's (1990) Multidimensional Perfectionism Scale; FMPS = Frost et al.'s (1990) Multidimensional Perfectionism Scale; APS$\mathrm{R}=$ Slaney et al.'s (2001) Almost Perfect Scale-Revised. SPP = socially prescribed perfectionism; COM = concerns over mistakes; $\mathrm{DAA}=$ doubts about actions; APS-D = discrepancy; OOP = other-oriented perfectionism; SOP = self-oriented perfectionism; FMPS$\mathrm{PS}=$ personal standards; APS-S = high standards; APS-O = order. 